\title{
Turismo de Base Comunitária sob influência do processo de Proteção da Natureza na Reserva Extrativista Prainha do Canto Verde (CE) e na Reserva de Desenvolvimento Sustentável do Aventureiro (RJ)
}

\author{
Community-based Tourism under the influence of Nature \\ Protection process in the Extractive Reserve Prainha do Canto \\ Verde (CE, Brazil) and the Sustainable Development Reserve \\ Aventureiro ( $R J$, Brazil)
}

Teresa Cristina de Miranda Mendonça, Edilaine Albertino de Moraes

\begin{abstract}
RESUMO:
Este artigo apresenta como discussão temática o turismo de base comunitária sob influência do processo de proteção da natureza, que tem como estratégia a criação de Unidades de Conservação, das categorias Reserva Extrativista e Reserva de Desenvolvimento Sustentável. Neste contexto, considera-se a lógica peculiar da dinâmica social, ambiental e cultural da Reserva Extrativista Prainha do Canto Verde (Ceará) e da Reserva de Desenvolvimento Sustentável do Aventureiro (Rio de Janeiro). O objetivo do trabalho se define na descrição e análise sobre o processo de fortalecimento do turismo de base comunitária sob influência das Unidades de Conservação instituídas na área abrangente da Prainha do Canto Verde e da Vila do Aventureiro. O caminho metodológico de trabalho compreendeu pesquisa bibliográfica, documental e de campo, desde 2003, considerando dados de projetos de pesquisa e extensão universitária, como possibilidade de cobertura ampla de fenômenos semelhantes, permitindo uma comparação dos resultados obtidos para ampliar as perspectivas de análise temática. O resultado principal alcançado na pesquisa se baseia na importância da criação da Reserva Extrativista Prainha do Canto Verde e da Reserva de Desenvolvimento Sustentável do Aventureiro para a valorização e validação do turismo de base comunitária, garantindo sua premissa básica: a concepção, o planejamento, a operação e a gestão do turismo pelos agentes locais.
\end{abstract}

PALAVRAS-CHAVE: Turismo de Base Comunitária; Proteção da Natureza; Reserva Extrativista Prainha do Canto Verde; Reserva de Desenvolvimento Sustentável do Aventureiro. 


\begin{abstract}
This paper discusses Community-based Tourism influenced by the process of nature protection and the strategic creation of Conservation Units, and the categories Extractive Reserve and Sustainable Development Reserve. In particular, we approach the peculiar logic of the social, environmental and cultural dynamics of the Extractive Reserve of Prainha do Canto (Ceará,Brazil) and the Sustainable Development Reserve of Aventureiro (Rio de Janeiro, Brazil) to describe and analise the reinforcement of Community-based Tourism in the conservation units created in these Reserves. The methodology includes bibliographical, documental and field research conducted since 2003, and the extension and research academic projects covering similar phenomena to enable a comparison of the findings to widen the perspectives of the analysis. The main findings point to the relevance of the creation of Reserves for valorization and validation of Community-based Tourism assuring its basic assumption: the conception, planning, operation and management of tourism by local agents.

KEYWORDS: Community-based Tourism; Nature Protection; Extractive Reserve; Sustainable Development Reserve.
\end{abstract}

\title{
Introdução
}

O turismo representa um fenômeno socioeconômico complexo que se realiza no âmbito local, envolvendo uma multiplicidade de abordagens cultural, ambiental e política, desempenhando, assim, um papel fundamental de articulação entre o lugar e o mundo. Porém, o turismo tem sido definido, predominantemente, pelos padrões impostos pela "indústria globalizada", a qual implica na promoção do crescimento econômico, gerando sinais evidentes de desigualdades econômicas e sociais. Resultado que leva ao questionamento do discurso turístico como atividade propulsora de desenvolvimento ao se constatar, em alguns casos, a marginalização de alguns sujeitos e atores fundamentais no processo de tomada de decisão, assim como no de geração de benefícios pelo turismo.

Além das preocupações com as questões socioeconômicas envolvidas, é fundamental também enfatizar os impactos ambientais inerentes a este processo, tendo em vista o interesse crescente por práticas turísticas associadas às áreas naturais preservadas, influenciado, sobretudo, pela popularização da questão ambiental e pelo ritmo acelerado do processo de urbanização. Estas são algumas questões que mostram a relevância de investigações sobre perspectivas, relações e modos de construção de práticas turísticas alternativas integradas a processos de proteção da natureza, que podem contribuir para a configuração de iniciativas classificadas como sustentáveis social e ambientalmente.

Visto sob este pressuposto, o presente artigo tem como foco temático principal o que tem sido designado de turismo de base comunitária ou turismo comunitário (TBC), desde a década de 1990, por iniciativas brasileiras. Experiencias que se destacam por práticas de valorização dos elementos culturais locais e de proteção dos recursos naturais, permitindo a geração de benefícios diretos e indiretos aos atores sociais locais envolvidos em todo 0 
processo. Nestas iniciativas, atores locais de diversos núcleos turísticos têm se inserido de forma mais efetiva no planejamento, execução e gestão das atividades do setor e conseguido gerar emprego e renda complementar. $\mathrm{Da}$ mesma forma, estes têm iniciado um movimento de resistência à megaprojetos turísticos, os quais possuem objetivos e interesses que negligenciam o contexto de necessidades básicas sociais locais e de vulnerabilidade ambiental, e que buscam uma consequente degradação ambiental e exclusão territorial dos que vivem nesses lugares, muitos considerados como populações tradicionais, que envolvem áreas de rica biodiversidade (MENDONÇA; MORAES, 2012).

Sendo assim, grande parte das iniciativas de TBC no Brasil surge em lugares de grande riqueza ecossistêmica e, consequentemente, de beleza cênica, vistos pelo empresariado como mercadoria potencial para o desenvolvimento turístico. $\mathrm{E}$ os ambientes litorâneos são exemplos que marcam a estratégia utilizada para a comercialização de diversos destinos turísticos brasileiros para diferentes públicos (MENDONÇA; MORAES; MACIEL, 2013). Nesta lógica de mercantilização dos espaços naturais e de apropriação destes espaços por agentes externos diante de um processo de exclusão socioespacial, diversas iniciativas de turismo de base comunitária estão articuladas a um movimento sociopolítico direcionado à reivindicação dos atores sociais locais pela: posse da terra, pela permanência no lugar onde nasceram e vivem, pelo direito à moradia, entre outros (MENDONÇA; MORAES, 2012).

Neste sentido, muitos grupos sociais, apoiados por organizações da sociedade civil organizada, têm utilizado como uma importante estratégia de defesa e luta pelo território a instituição da área em Unidade de Conservação do Grupo Uso Sustentável, sobretudo, das categorias Reserva Extrativista (RESEX) e Reserva de Desenvolvimento Sustentável (RDS), conforme o Sistema Nacional de Unidades de Conservação da Natureza - SNUC, Lei $9985 / 2000$ e Decreto 4340/2002. Isso porque, segundo o SNUC, tanto a categoria RESEX quanto a RDS são áreas naturais, sejam em qualquer bioma brasileiro, que abrigam populações tradicionais, ao longo de gerações, cuja existência baseia-se em exploração sustentável dos recursos naturais, que desempenham um papel fundamental na proteção da natureza e, ao mesmo tempo, na reprodução e melhoria dos modos culturais e de vida destas populações, além de permitirem e incentivarem a visitação pública (BRASIL, 2000, 2002).

O turismo desenvolvido em Unidades de Conservação de Uso Sustentável da categoria RESEX e RDS tem sido um desafio para a pesquisa e políticas públicas no Brasil (MORAES et al, 2007; MORAES; IRVING, 2009, 2013). Espaços formais e informais de diálogo e articulação coletiva têm sido construídos, sobretudo, no âmbito dos Encontros Nacionais de Turismo de Base Local ENTBL (desde São Paulo/SP, 1997), das edições do Fórum Social Mundial (desde Porto Alegre/RS, 2005), dos Encontros da Rede Brasileira de Turismo Solidário e Comunitário - TURISOL, e dos desdobramentos das ações do Ministério do Turismo por meio da Chamada Pública de Apoio a 50 (cinquenta) Iniciativas de Turismo de Base Comunitária (Edital no 001/2008), possibilitando a reflexão crítica sobre um amplo conjunto de perspectivas e projetos orientados, sobretudo, pelo modo de organização comunitária e 
atividades produtivas, e que contemplam áreas de interior e/ou entorno de Unidades de Conservação. Assim, O TBC se insere nas discussões de trabalhos científicos e de políticas públicas como uma possibilidade de uma nova relação turismo-natureza-comunidade local.

Em iniciativas de turismo de base comunitária como a da Prainha do Canto Verde (Beberibe/CE) e a da Vila do Aventureiro (Ilha Grande, Angra dos Reis/RJ), são identificadas duas localidades representadas por um modo anterior de vida essencialmente pesqueira, e com práticas agrícolas de subsistência e de pequena escala, que passam a ser permeadas por uma nova lógica econômica, ditada pela introdução do turismo entendido como uma nova alternativa para o desenvolvimento local. É possível, então, constatar que a população local tem se apropriado, a seu modo, das imposições do mercado, transformando-as e fazendo uso delas de acordo com seus valores demarcados culturalmente, de forma atrelada às regulações impostas pela legislação competente das Unidades de Conservação criadas na área habitada, sendo no primeiro caso a RESEX Prainha do Canto Verde (2009) e, no segundo, parte da Reserva Biológica da Praia do Sul - RBPS (1981) e do Parque Marinho do Aventureiro - PEMA (1990) recategorizados em RDS do Aventureiro (2014).

Considerando a lógica peculiar da dinâmica social, ambiental e cultural de cada lugar em questão, este artigo objetiva fazer uma análise sobre a relação do turismo de base comunitária com o processo de proteção da natureza. Especificamente, objetiva-se descrever e analisar o processo de fortalecimento do turismo de base comunitária sob influência das Unidades de Conservação instituídas na área abrangente da Prainha do Canto Verde (CE) e da Vila do Aventureiro (RJ).

A escolha dos estudos de caso se justifica por ambos representarem espaços costeiros-marinhos vulneráveis à especulação imobiliária, à urbanização e ao turismo em massa, nos quais os moradores locais desenvolvem práticas de TBC reconhecidas com base em princípios diferenciados, sendo essas localidades influenciadas por realidades distintas quanto ao processo de criação de UCs. A Prainha do Canto Verde passou por um longo processo de organização e luta dos seus moradores contra 0 processo de grilagem de terra, desde a década de 1970, culminando com o direito ao acesso à terra, ao ambiente marinho e aos recursos pesqueiros por meio da criação de uma RESEX. A Vila do Aventureiro foi inserida, desde a década de 1980, nas categorias de UC do Grupo de Proteção Integral Reserva Biológica e Parque, o que impôs aos moradores locais diversas tensões e ameaças de expulsão, provocando um amplo movimento para regularizar a situação da presença humana no lugar, por meio da conquista de recategorização da área para uma RDS.

O caminho metodológico de trabalho compreendeu pesquisa bibliográfica, documental e de campo, desde 2003, considerando dados de projetos de pesquisa e extensão universitária, como possibilidade de cobertura ampla de fenômenos semelhantes, permitindo uma comparação dos resultados obtidos para ampliar as perspectivas de análise temática. 


\section{Prainha do Canto Verde: Turismo Comunitário e a Reserva Extrativista}

Localizada no município de Beberibe, a Prainha do Canto Verde abrange uma área de 749 hectares com praia de aproximadamente $5 \mathrm{Km}$ de extensão. A localidade Prainha do Canto Verde é reconhecida, amplamente, como uma das comunidades de pesca artesanal mais organizada do Estado do Ceará. Populações pesqueiras, como a da Prainha do Canto Verde, possuem uma relação estreita com o mar. Mas o elemento terra também é importante em seu modo de vida, uma vez que é o espaço de realização de trabalhos manuais artesanais como bordados, labirintos, rendas, além de pequenos plantios de subsistência. Porém, nos últimos tempos, o que mais tem atraído o olhar e a visita de um público diverso à Prainha do Canto Verde é a comunidade local e o seu modo de organização coletiva.

Com cerca de 1.100 moradores locais, o processo de organização comunitária na Prainha do Canto Verde foi incentivado pela questão da terra (MENDONÇA, 2004). A comunidade lutou por mais de vinte anos, pela posse da terra contra grileiros e agentes imobiliários. Todo esse processo foi influenciado por sua localização em uma faixa litorânea de elevado valor econômico, que envolve os principais destinos da região turística cearense Costa Sol Nascente: Porto das Dunas (Aquiraz), Praia das Fontes e Morro Branco (Beberibe) e Canoa Quebrada (Aracati).

O litoral cearense, na década de 1990, foi palco de diversos impactos socioambientais gerados, principalmente, pelas ações adotadas para 0 desenvolvimento do turismo no Estado, resultante do Programa de Desenvolvimento do Turismo no Nordeste (PRODETUR), criado pelo governo federal. As ações implementadas implicaram grandes transformações espaciais, culturais, econômicas, sociais e ambientais, geradas pela especulação imobiliária, pela apropriação de terras dos pequenos grupos comunitários presentes na área, pelos conflitos de terra e pela privatização e degradação de espaços públicos (CORIOLANO, 2001). Neste contexto, os antigos ocupantes das demais praias de Beberibe foram, gradativamente, assaltados pela lógica mercantil do uso e ocupação do solo. Logo, o território usado pelos pescadores, pequenos agricultores e artesãos que ali residiam se tornou alvo da cobiça de investidores que, ao contrário dos nativos, viram - território apenas como um recurso para reprodução do capital (MENDONÇA, 2004).

Em uma perspectiva diversa da maioria dos moradores da região, a comunidade da Prainha do Canto Verde decidiu enfrentar e resistir ao modelo de desenvolvimento que estava sendo imposto pelo PRODETUR no litoral cearense, em prol da garantia do direito de se manter no lugar de origem. Sendo assim, o processo de organização comunitária local começou a se expressar com a criação da Associação dos Moradores da Prainha do Canto Verde, em 1989, em ação conjunta com as Comunidades Eclesiais de Base, movimento ligado à Igreja Católica. A Associação passou a representar o núcleo central e norteador das atividades e a se estruturar por meio de conselhos comunitários de educação, pesca, saúde e turismo e, posteriormente, o surgimento dos conselhos de cidadania e ética para melhor atender às demandas locais. A história de organização, luta e resistência da Prainha do Canto Verde foi marcada pelo papel instituído pelas famílias locais que buscavam sensibilizar e fortalecer o sentimento de pertencimento a terra 
e os laços comunitários e afetivos para encorajar os moradores a lutar contra os poderosos agentes econômicos e políticos.

Os moradores perceberam que a chegada do turismo na Prainha do Canto Verde era inevitável, levando às primeiras discussões sobre o tema em 1993 e 1994. Desde então, o turismo foi pauta das reuniões da Associação dos Moradores, aparecendo como oportunidade de geração de emprego e renda complementar a pesca, e ocupação profissional para os jovens da localidade. Por outro lado, os moradores perceberam que a exploração do lugar por agentes turísticos externos potencializava os riscos ligados à venda de terras, à prostituição, ao roubo e outros impactos que ameaçavam o modo e a vida do lugar. Por esta razão, foi construído o "Projeto Turístico Socialmente Responsável" da Prainha do Canto Verde, partindo da premissa básica de "ouvir a voz" dos moradores locais. Segundo Mendonça (2004, p. 108), os moradores se identificavam com a construção de um sistema diferente: "um turismo onde nós somos os articuladores, construtores, donos de empreendimento, organizadores e onde a renda e o lucro ficam dentro da comunidade, para melhorar a nossa qualidade de vida e não a dos outros".

Neste contexto, a "Primeira Oficina de Turismo" ocorreu em 1994 e resultou na criação de um conselho de turismo e na identificação do desenvolvimento de dois tipos de turismo: o "Turismo dos Barão", que seria aquele em que "Eles decidem e ficam com o lucro e Nós obedecemos e ficamos com o prejuízo" e "O Nosso Turismo", aquele em que "Nós aprendemos. Nós decidimos. Nós mandamos. Ficamos independentes.", intitulado por eles mesmos de turismo comunitário (MENDONÇA, 2004).

Assim, a proposta de turismo da Prainha do Canto Verde foi influenciada pelos seguintes elementos marcantes da vida no lugar: a garantia da posse da terra, a definição da propriedade e da gestão dos empreendimentos pelos próprios moradores, e o turismo como atividade complementar a pesca (MENDONÇA; MORAES; MACIEL, 2013). Sob essas premissas, entende-se que o turismo na Prainha do Canto Verde se diferencia dos destinos convencionais do litoral cearense, por ter construído um modelo planejado e gerenciado pelas próprias populações pesqueiras, que contribui para a melhoria dos padrões socioeconômicos e o respeito e valorização da cultura dos "Povos do Mar". Como resultado, o turismo comunitário da Prainha do Canto Verde se tornou uma referência para outras populações pesqueiras que viviam realidades semelhantes, impulsionando a criação da Rede Cearense de Turismo Comunitário - REDE TUCUM lançada oficialmente, em 2008, durante o II Seminário Internacional de Turismo Sustentável - SITS.

Neste contexto, o turismo comunitário também foi entendido como uma estratégia de visibilidade da luta e resistência em defesa da terra. A luta pela permanência dos moradores da Prainha foi influenciada pelos discursos construídos localmente e partilhado pela Associação dos Moradores: "A terra é nossa e não abrimos mão dela". "Ajudemos a preservar a terra para nossos filhos. Lei Federal Proíbe a venda de terras da união. "Se você acha que é certo vender terra, diga: aonde nossos filhos vão morar quando a terra for toda vendida?". (MENDONÇA, 2004). Diante do discurso de tornar o local de moradia e produções culturais em terra pública, para evitar a distribuição de titulação de propriedade privada, a outra estratégia de resistência em defesa da terra vislumbrada pelos moradores da Prainha do Canto Verde foi a 
instituição de uma Unidade de Conservação na área, da categoria de manejo Reserva Extrativista. Assim, em 2001, a Associação de Moradores encaminhou ao Instituto Brasileiro de Meio Ambiente e de Recursos Naturais Renováveis (IBAMA), que era o órgão competente na época, o pedido de criação de uma Reserva Extrativista na área ocupada tanto no ambiente terrestre quanto no marinho. Durante este período, ocorreu a vitória da ação rescisória dos moradores da Prainha do Canto Verde contra a entrada de usucapião da área pela Imobiliária Henrique Jorge, pronunciado pelo Supremo Tribunal de Justiça, em 14/03/2006. No entanto, permaneceu a preocupação com a organização da ocupação do espaço e com a forma de dar continuidade ao espírito de luta comunitária para a garantia de permanência dos moradores no local herdado.

Após quase 10 anos, a Reserva Extrativista Prainha do Canto Verde foi oficializada pelo decreto $\mathrm{S} / \mathrm{N}$ de $05 / 06 / 2009$, proporcionando à população pesqueira o direito garantido de posse a terra firme e a parte de mar necessária para a prática da pesca artesanal. Caracterizada pelo bioma marinho-costeiro, a área decretada foi de aproximadamente 29.794 ha, dentre esses, 577,55 compõem a parte terrestre. Os instrumentos, plano de manejo e acordo de gestão, ainda não foram elaborados e aprovados pelo seu conselho gestor deliberativo, instituído pela Portaria 125/2010 com 19 representações, sendo 10 comunitárias e 9 parceiros externos. Mas o conselho dispõe da Resolução no 01/2011, em que estabelece procedimentos administrativos para autorização de construções de moradia e quarto de pesca; e da Resolução oㅡ 02/2012, em que estabelece procedimentos administrativos para 0 controle, regulação e ordenamento para 0 desenvolvimento da atividade pesqueira artesanal dentro dos limites da RESEX Prainha do Canto Verde (MENDONÇA; MORAES; MACIEL, 2013). A forma de organização regimental do conselho prevê uma coordenação colegiada com quatro assentos, sendo um cativo ao ICMBio e os demais abertos a participação de seus membros. Para Brito, Ferreira e Machado (2014), esta é uma prática inovadora de gestão fundamental para a diversificação dos olhares no pensar do fazer, o aumento do senso crítico e a divisão das responsabilidades de gestão do conselho com os seus membros.

Apesar da maioria dos moradores ter apoiado a criação da RESEX, observa-se, em 2012, a formação da Associação Independente dos Moradores da Prainha do Canto Verde e Adjacências (AIMPCVA) por integrantes dissidentes da Associação dos Moradores da Prainha do Canto Verde, que move uma ação ordinária contra o atual órgão administrador Instituto Chico Mendes de Conservação da Biodiversidade (ICMBIO) e a União, questionando a instituição da RESEX em área continental, uma vez que, dessa forma, os moradores não podem mais fazer pequenas construções ou reformas em suas casas, e nem vendê-las. Destaca-se que a Associação Independente é apoiada por um empresário que entrou com uma ação de usucapião para legalizar 315 hectares de terra na Prainha do Canto Verde. Este movimento resultou no conflito que, atualmente, divide os moradores, com a intenção de excluir a área terrestre da RESEX (MENDONÇA; MORAES; MACIEL, 2013).

Porém, segundo a nota de apoio e esclarecimentos sobre a RESEX Prainha do Canto Verde/CE, divulgada em 15 de março de 2013, a pesca 
artesanal e a relação com o mar são centrais para os moradores locais. Isso porque a vida comunitária acontece na terra, onde se constrói habitações e espaços coletivos; se realiza outros trabalhos, incluindo o de mulheres e jovens. Na terra, a comunidade vive os afetos, as relações familiares, o lazer, os encontros religiosos; e, nela, também, acessa os serviços públicos, como saúde e educação. A área de terra protegida também possibilita à comunidade conviver com o avanço do mar e outros eventos naturais como os movimentos das dunas, a partir da mudança de rota dos ventos. É na terra que as pessoas podem reconstruir as casas atingidas por esses fenômenos e formar novos núcleos familiares (MENDONÇA; MORAES; MACIEL, 2013).

Sendo assim, segundo a Associação dos Moradores da Prainha do Canto Verde,

a maioria dos moradores estão felizes com a Resex e a garantia do uso da terra para eles e as futuras gerações e o direito de uso dos recursos na parte marinha da Resex. Só falta o Governo assinar o CCDRU - Contrato de Concessão de Direito Real de Uso (PRAINHA DO CANTO VERDE, 2012 apud MENDONÇA; MORAES; MACIEL, 2013).

Outro trabalho que corrobora a importância da RESEX é o relatório técnico do ICMBIO (2011), que recomenda desconsiderar a possibilidade de redução dos limites da UC na parte terrestre ou marinha, e sim ampliar os seus limites para proporcionar a sustentabilidade da comunidade em longo prazo. Então, parece que o processo de criação da RESEX Prainha do Canto Verde está regularizado e o órgão gestor está encaminhando as ações devidas para a sua consolidação (MENDONÇA; MORAES; MACIEL, 2013).

Portanto, pode-se considerar a criação da RESEX Prainha do Canto Verde como resultado de um processo histórico de participação, de luta e resistência dos moradores locais que se autodenominam por "Prainheiros". A RESEX foi decretada 16 anos depois que a comunidade local começou a discutir a respeito de um projeto turístico, em um contexto de gestão local, caracterizada pela forte mobilização dos conselhos comunitários participativos e consultivos, e que se baseia em uma relação de complementaridade com a pesca. A criação da RESEX também garantiu o controle do turismo pelos moradores em todos os elos da cadeia produtiva local, em contraponto ao padrão convencional marcante na região turística cearense Costa Sol Nascente, sem a exploração de agentes externos (MENDONÇA; MORAES; MACIEL, 2013).

\section{Vila do Aventureiro: Turismo de Base Comunitária e recategorização de Unidades de Conservação}

A Vila do Aventureiro está localizada na Ilha Grande, que é a segunda maior ilha oceânica brasileira (193 km²), um dos maiores patrimônios naturais do Estado do Rio de Janeiro e um dos últimos remanescentes preservados de Mata Atlântica. Devido à riqueza e importância do ecossistema da Ilha Grande foram criadas quatro Unidades de Conservação: o Parque Estadual da Ilha Grande - PEIG (1971), a Reserva Biológica da Praia do Sul - RBPS (1981), a 
Área de Proteção Ambiental de Tamoios - APA Tamoios (1982) e o Parque Estadual Marinho do Aventureiro - PEMA (1990). As medidas para a proteção do ecossistema da llha implicaram no estabelecimento e no avanço das preocupações com as "questões ambientais" da região. Esse processo contribuiu para transformar a natureza conservada no principal produto potencial para o turismo se transformar em uma possível alternativa de sobrevivência para os moradores da llha Grande, incentivado também pela crise pesqueira (MENDONÇA, 2010).

No entanto, a llha Grande passa a ganhar status oficial de destino turístico, principalmente, após a extinção do Instituto Penal Cândido Mendes, em 1994, na Vila Dois Rios (COSTA et al, 2009). A partir deste marco, a funcionalidade do ambiente insular baseada nos serviços ligados ao presídio e à pesca foi alterada pela força dos elementos da natureza - "mata verde, mar azul" - como principal recurso a ser explorado economicamente. A imposição de outra lógica na dinâmica socioambiental e cultural, atravessados por uma nova lógica econômica, ditada pela introdução do turismo significou uma ruptura com os modos anteriores de vida pesqueira e agrícola (MENDONÇA, 2010).

No âmbito da llha Grande, se insere a Vila do Aventureiro localizada na parte sul voltada para o mar aberto com aproximadamente 800 metros de extensão, e habitada há cerca de 150 anos por uma população de agricultores pescadores denominados como "caiçaras" (COSTA, 2004). No Aventureiro, foram criadas duas das unidades de conservação da natureza mencionadas anteriormente, pertencentes ao Grupo de Proteção Integral: a Reserva Biológica da Praia do Sul - RBPS (Decreto Estadual No 4.072/1981) e o Parque Estadual Marinho do Aventureiro - PEMA (1990). Instaurou-se assim, um intenso conflito socioambiental do Estado do Rio de Janeiro, no que se refere às consequências da existência dessas UCs de Proteção Integral sobre a vida dos moradores. A Reserva Biológica impedia a permanência dos moradores no local, já estabelecido há gerações na região, e a área marinha da categoria Parque não permitia o uso dos recursos pesqueiros. Consequentemente, o turismo não seria permitido nessa área. Destaca-se que, neste caso, a luta para permanecer no território herdado se instituiu entre os moradores locais e o governo do Estado do Rio de Janeiro.

Este é um caso específico da llha relacionado à crise pesqueira e à criação de Unidades de Conservação em um lugar onde a natureza foi um dos poucos recursos que restou aos moradores do local. Há diversas gerações, a atividade de subsistência do Povo do Aventureiro estava ligada à exploração dos recursos naturais como a pesca nas praias, caça eventual, a agricultura doméstica, voltada principalmente para a produção de farinha de mandioca, mas a renda também estava vinculada ao salário dos moradores que trabalhavam com pesca assalariada (VILAÇA; MAIA, 2006). As medidas de proteção da natureza no Aventureiro, e consequente restrições de seu uso, fizeram com que restasse aos moradores apenas o turismo, como a única alternativa econômica para a sobrevivência (MENDONÇA, 2010).

Sendo assim, o Aventureiro tornou-se um "atrativo turístico", mesmo sendo colocada em uma redoma para proteção de grande variedade de espécies da fauna e da flora terrestre e aquática disponíveis na área, para se transformar em um laboratório aberto de pesquisas científicas. Este caso 
mostrou como nenhuma categoria de Unidade de Conservação tão restritiva, como a REBIO, impediu que seus moradores continuassem dentro de sua área vivendo de atividades ligadas, de forma direta ou indireta, ao turismo. Por outro lado, a criação da RBPS influenciou o processo de consolidação da imagem do Aventureiro como o "paraíso idílico", "lugar exótico", "símbolo do natural", do "primitivo", do "único", "pedaço do paraíso perdido do povo caiçara tradicional". Sua imagem é influenciada, principalmente, pela ausência de um processo de turistificação e de crescimento urbano, tal como a Vila do Abraão (conhecida como a capital da llha Grande) e demais localidades deste ambiente insular, assim como pela ausência de energia elétrica e pela manutenção do padrão das casas originais (MENDONÇA, 2010).

Deste modo, o turismo ali se desenvolveu de forma diferenciada das demais enseadas da Ilha Grande, sem especulação imobiliária e crescimento urbano, sem transformação da paisagem ou mesmo a privatização de praias e trilhas, sem cheiro de esgoto e imigração. Esse modo peculiar faz com que Prado (2005, p.14) caracterize a Vila do Aventureiro como "...a única praia da Ilha em que a comunidade local tomou inteiramente em suas mãos a condução do turismo que ali ocorre, totalmente a seu jeito". Ou conforme citado por Costa (et al., 2009, p. 177), "...um caso sui generis de relação da população local com o turismo gestão local do turismo". No entanto, o modelo de turismo predominante na llha que privilegia àqueles com grande aporte de capital econômico para a gestão do turismo representa uma ameaça ao Aventureiro.

Em um ambiente de incompatibilidade entre leis e práticas locais, o turismo foi considerado por Costa (2004) como uma atividade "tabu" tanto para moradores, quanto para a Fundação Estadual de Engenharia do Meio Ambiente - FEEMA (antiga gestora da RBPS) e ambientalistas. No entanto, a visitação a uma reserva biológica (uma atividade "tabu") foi um diferencial do turismo no Aventureiro (MENDONÇA; FONTOURA, 2009). Como resultado, o turismo no Aventureiro se baseia em uma cadeia produtiva caracterizada por empreendimentos domiciliares e familiares, que não possuem o aspecto físico de empreendimentos turísticos convencionais no mercado, pois, por serem contíguos às casas, continuam tendo aspecto residencial. A estrutura de campings nos quintais, aluguel de quartos, casas e bares anexos às casas dão o tom domiciliar aos empreendimentos pela discreta e, muitas vezes, imperceptível diferença entre o local de moradia e o empreendimento comercial. Além disso, alguns moradores oferecem sua estrutura domiciliar aos visitantes (quartos, banheiros, sala de estar, cozinha). Os dois ambientes, muitas vezes, se mesclam: o modo doméstico de receber (incluindo o modo de vida cotidiano na residência) e o modo comercial, na relação entre hóspede - o cliente - e anfitrião - o profissional, baseado na troca monetária. Esse processo diferencia o modelo de turismo local baseado em uma nova relação entre anfitriões - o "povo do Aventureiro" - e hóspedes - os "turistas aventureiros", e resulta em um relacionamento que, muitas vezes, cria laços de amizade entre esses atores, extrapolando as relações comerciais (MENDONÇA; MORAES, 2011).

Ferreira (2004) detectou que $46 \%$ dos moradores estavam envolvidos com as atividades ligadas diretamente ao turismo. Segundo Mendonça e Moraes (2011), no período de 2009 e 2010, foi também registrado que 75\% 
dos moradores estão envolvidos direta ou indiretamente com atividades ligadas ao turismo. Assim, constata-se a apropriação, cada vez maior, pelos moradores do Aventureiro das atividades ligadas ao turismo, com o aumento de $29 \%$, em cinco anos, do número de residentes envolvidos diretamente com o turismo. É importante ainda destacar que, 65\% dos empreendimentos ligados ao turismo são de posse e gestão de moradores nativos, sendo este perfil motivado pela presença da reserva biológica (MENDONÇA; BRANDÃO, 2010). Conforme Wunder (2006, p.171), não há dúvidas que a renda gerada pelo turismo tenha tido "um impacto revolucionário na economia local".

No entanto, o lugar já chegou a receber até seis mil turistas, conforme dados referentes ao Réveillon de 2005 (citados na reportagem do jornal 0 Globo de 13 de março de 2006), e uma média de três mil pessoas nos períodos de maior fluxo, segundo informações locais. Percebendo esse cenário crescente de visitação, a Vila do Aventureiro fez parte de um processo de criação de um critério de capacidade de carga e de controle de fluxo de visitantes para toda a Ilha Grande, discutido no âmbito dos diversos fóruns públicos instituídos na Ilha Grande. Assim, um Termo de Compromisso foi assinado em 26 de dezembro de 2006, em comum acordo entre a Prefeitura Municipal de Angra dos Reis, o Ministério Público Estadual, a Procuradoria Geral do Estado do Rio, a Fundação Estadual de Engenharia do Meio Ambiente - FEEMA e a comunidade, representada pela Associação de Moradores e Amigos do Aventureiro - AMAV. Neste foi estabelecido um limite na visitação para a área destinada ao camping de 560 pessoas por dia e um número máximo de 18 campings. No entanto, apesar de considerar que poderia ser aumentado o número proposto no Termo de Compromisso, os moradores da Vila do Aventureiro reconhecem que o atual controle de visitação contribuiu para melhor organizar o turismo local e proporcionar maior tranquilidade aos moradores e empreendedores. Assim como, eles reconhecem que por mais que a criação da Reserva Biológica tenha resultado em conflitos internos e externos e restrições diversas, paradoxalmente, protegeu os moradores locais da especulação imobiliária, da urbanização descontrolada, da chegada de novos moradores e da expulsão dos nativos do local herdado.

Perante a situação de "ilegalidade", o então Instituto Estadual de Florestas - IEF/RJ, transformado em diretoria do atual Instituto Estadual do Ambiente - INEA, iniciou um diálogo com a comunidade sobre a recategorização da área habitada através da instituição do Grupo de Trabalho Aventureiro - GT Aventureiro em 09/04/2008, por Resolução SEA no 057. O Grupo de Trabalho apresentou, em seu relatório final, a proposta de recategorizar a Vila do Aventureiro para Reserva de Desenvolvimento Sustentável - RDS. Uma vez que, representantes da AMAV submeteu uma carta elaborada pela própria comunidade local ao Grupo de Trabalho do Aventureiro do Instituto Estadual do Ambiente (INEA), em 22 de maio de 2010, solicitando a criação de uma Reserva de Desenvolvimento Sustentável do Aventureiro, a qual atenderia aos anseios e necessidades quanto à permanência da população no seu local de origem, à proteção dos recursos naturais e à forma de assegurar a cultura tradicional, inclusive à continuidade da atividade produtiva do turismo. Desde então, o Povo do Aventureiro se engajou em um processo de luta contra forças hegemônicas de poder 
econômico e político, articulando diversas frentes de apoio à criação da RDS, por meio de campanhas, abaixo-assinados, etc.

No entanto, o poder público estadual apresentou, inicialmente, duas propostas de nova categoria de uso sustentável: Área de Proteção Ambiental - APA ${ }^{1}$ e RDS, o que incluiria a área de mar atualmente abrangida pelo PEMA. Porém, quando o Estado retorna para mais um momento de negociação com a comunidade, ele apresenta apenas uma proposta, a RDS. A RDS é uma alternativa para que os moradores garantam o direito de uso das terras, mesmo que estas sejam de domínio público, com concessão de uso da área habitada para os moradores de forma vitalícia, a fim de que possam realizar atividades econômicas de baixo impacto. A proposta foi transformada em Projeto de Lei e passou por tramitação na Assembleia Legislativa do Estado do Rio de Janeiro.

Toda essa ação se traduziu essencialmente na legalização das atividades ligadas de forma direta ou indireta ao turismo. Tratou-se de um embate estabelecido desde a criação da Reserva Biológica, já que isso se deu por pressão de ambientalistas para evitar que a área fosse tomada pela especulação de grandes empreendimentos turísticos previstos a serem instalados. A questão a ser solucionada era: "Como tirar os moradores do Aventureiro da ilegalidade em que foram colocados, ao mesmo tempo em que possam continuar realizando o modelo de turismo que inventaram ali a seu próprio modo?"

De acordo com Mendonça e Fontoura (2009), a não unanimidade entre os moradores pela opção da nova categoria de unidade de conservação é percebida. Alguns moradores preferem a APA, categoria menos restritiva, o que significaria, pela visão e compreensão deles, o direito à venda de sua terra para pessoas de fora. Na outra ponta, um grupo considera que a RDS os protege dos agentes externos e dá garantia de mantê-los no lugar, assim como as futuras gerações. Nesse ambiente, posse, propriedade e liberdade para vender o imóvel, manutenção do lugar onde nasceram e vivem, direito de plantar e de realização de atividades ligadas ao turismo são itens de reivindicação dos moradores. Na verdade, todo o processo de discussão sobre a recategorização da área habitada da RBPS seguiu a Recomendação no 10/06 feita pelo Ministério Público do Estado do Rio de Janeiro (Inquérito Civil no 581/06), datado de 29 de agosto de 2006.

Assim, como resultado de todo processo, em 2014, foi aprovada a Lei № 6793/2014, em que estabeleceu a alteração dos limites da área, recategorizando parte da RBPS (com redução de $2,7 \%$ da porção terrestre) e integralmente o PEMA (porção marinha) para a RDS do Aventureiro, com 1.910 mil hectares. Nos termos do SNUC (Artigo 20 da Lei 9.985/2000), a criação da RDS do Aventureiro permitiu aos moradores locais permanecerem na área e conciliarem a preservação dos ecossistemas locais com a cultura caiçara, inclusive com a prática do turismo. Atualmente, após as providências referentes ao cadastramento da população beneficiária, iniciou-se o processo de formação do Conselho Gestor da RDS. 


\section{Considerações finais}

Neste contexto de análise proposta, foi possível reafirmar, segundo pesquisas de Moraes e Irving $(2009$, 2013) que Unidades de Conservação associadas ao modo de vida tradicional, como são os casos da RESEX e RDS, são "destinos singulares" para uma prática alternativa às formas convencionais de turismo, como o turismo de base comunitária. E no caso da prática turística em espaços litorâneos protegidos, a disputa é mais ampla para novos usos e ocupações, se tornando a principal mercadoria imobiliária, causando segregação das populações ditas tradicionais e nativas. Dessa forma, a "indústria" do turismo e sua implantação nos espaços litorâneos trouxeram muitos benefícios, mas também muitos problemas sociais, culturais e ambientais como: especulação imobiliária, redefinição do perfil da população local, processo de imigração, degradação ambiental, desmantelamento da paisagem, marginalização socioespacial e econômica de populações tradicionais, etc.

O caso da Prainha do Canto Verde, diante de uma luta comunitária contra o mercado e os grandes agentes imobiliários e do capital turístico, mesmo com os resultados alcançados com a implantação do Projeto Turístico Socialmente Responsável, os moradores locais percebem que ainda existe uma diferença entre a comunidade que é realidade e a de seus sonhos, a idealizada. O núcleo pesqueiro artesanal da Prainha, considerada de alto nível de organização e participação, que cansada de esperar do Estado soluções para a melhoria da qualidade de vida, conseguiu não ser "engolido" pela lógica do mercado turístico predominante no estado do Ceará, e no litoral brasileiro, buscou o engajamento, a articulação e a autonomia para o desenvolvimento de seus próprios projetos e soluções locais. No entanto, atualmente, os conflitos internos se baseiam em visões locais sobre o modelo de propriedade da terra. Depois de anos de luta por uma terra pública, o conflito interno aflora por um grupo que defende a terra comunitária (permitida pela instituição da RESEX), e por outro que defende uma terra com títulos individuais, privados. No entanto, a consolidação da criação da RESEX Prainha do Canto Verde garante que levem adiante o sonho da terra pública e do modelo de turismo comunitário, onde seus moradores, a maioria nativos, são os proprietários e gestores dos negócios turísticos.

Na Vila do Aventureiro, o processo de recategorização de UC para uma do tipo Uso Sustentável foi resultado de uma exigência do Ministério Público para que o Estado do Rio de Janeiro corrigisse um erro ao criar uma UC de Proteção Integral tão restritiva sobre uma população que já morava no lugar há gerações e que eram vistos como ameaça à proteção da natureza. Assim, durante anos, sob a tutela do órgão ambiental, as atividades ligadas ao turismo oscilaram no passado entre uma concessão ambígua ("vista grossa"), a proibição total pela fiscalização e o apoio ao turismo de base comunitária diante de um projeto de controle de acesso e capacidade de carga. Desta forma, constatou-se que, por mais que a criação da RBPS tenha resultado em conflitos e restrições diversas, ela, paradoxalmente, protegeu os moradores do Aventureiro de grandes problemas socioambientais presentes em grande parte da llha Grande. A retirada do Povo do Aventureiro do interior da RBPS 
poderia representar perigo ao permitir a ocupação do lugar pelos agentes externos, se a área fosse recategorizada como APA.

Assim, a especificidade do turismo do Aventureiro é marcada especialmente por um modelo de empreendimento com divisão de trabalho familiar, essencialmente por moradores com direitos históricos de permanência no local herdado, caracteriza-se justamente pelo diálogo e/ou disputa com o modelo de gestão ambiental. Dialogando com o novo modelo de gestão, em uma perspectiva presente e futura, o Povo do Aventureiro começa a pensar na operação do turismo em um "paraíso não mais proibido", dispondo sobre os direitos, os deveres e o zoneamento preliminar no processo de elaboração do Plano de Manejo e da constituição do Conselho Deliberativo da RDS do Aventureiro.

É importante destacar a diferença do processo de criação das UCs em cada estudo de caso. A Prainha buscou ser inserida em uma categoria de UC, pois anteriormente suas terras estavam mais restritas a alguns e títulos de propriedade por ser terra da Marinha (praias e dunas). Na Vila do Aventureiro, a busca pela recategorização foi feita com o objetivo de minimizar os efeitos da criação de uma UC de Proteção integral sem a tomada de uma decisão conjunta entre Estado, moradores e sociedade civil. Ou seja, para corrigir um erro histórico ali instituído. Assim, estar condicionada às normas, regras e limites impostos pela instituição de uma UC, mesmo sob a categoria de usos sustentável, foi uma opção dos moradores da Prainha do Canto Verde, o que não aconteceu na Vila do Aventureiro. Estes últimos foram obrigados a se inserirem em uma lógica ambientalista que impôs novas regras locais. Acima de tudo, destaca-se que ambos os processos envolvem conflitos, contradições e reações.

Portanto, os casos apresentados e suas iniciativas de turismo permitem também refletir sobre a política pública nacional e estadual de criação de UC onde a cultura de criação de categorias de uso integral supera a de usos sustentáveis, principalmente no que diz respeito às RESEX e RDS. No estado do Rio de Janeiro, a RDS do Aventureiro é a única desta categoria presente entre diversas APAs e demais de proteção integral.

Em várias regiões brasileiras, assim como no litoral, o turismo surge como alternativa de desenvolvimento local. Deve-se, então, levantar a questão de como as comunidades podem participar efetivamente dos benefícios advindos das atividades geradas pelo setor. Os projetos de desenvolvimento turístico têm se constituído pelo benefício efetivo dos agentes externos, negligenciando a participação dos locais na tomada de decisões, assim como na melhor distribuição dos resultados. Em resposta a este modelo de desenvolvimento, os moradores da Prainha do Canto Verde e a da Vila do Aventureiro criaram seu próprio modelo de turismo classificado como de base comunitária. Uma proposta criada em contraponto aos modelos de desenvolvimento caracterizados por ações de exclusão e a promoção do crescimento das desigualdades sociais. Estes modelos locais de turismo foram construídos em um cenário de lutas permanentes contra agentes externos (grileiros, agentes imobiliários, empresários, poder público, poder judiciário, entre outros). 
A defesa de ambas comunidades na luta pela permanência no local herdado tem como referência o uso do espaço baseado na condição do "direito nato". Esta afirmativa é evidenciada pelos relatos orais pesquisados em Mendonça $(2004,2010)$. Nos discursos permanentes declaram-se, no caso da Prainha do Canto Verde, os moradores vivem no lugar há cerca de 140 anos e no caso do Povo do Aventureiro, os moradores vivem no local há cerca de 150 anos. Logo, entende-se que a construção da identidade de cada lugar está diretamente relacionada à reconstrução que estas populações fazem do passado a partir dos conflitos e tensões vividos no presente. A criação da RESEX e da RDS garante estes direitos e os protegem de processos ligados às exclusões socioespaciais por qual estavam ameaçados, seja pelo Estado ou pelo agente do capital, atualmente ligado principalmente ao turismo, assim como de um modelo de turismo classificado como de massa.

Salienta-se ainda que o tema sobre a relação entre turismo e UCS de uso sustentável (RESEX e RDS) cumpre a função de ampliar o debate político ambientalista para incluir direitos sociais e culturais ignorados pelo Estado ou pelos atores hegemônicos. Acredita-se, então, na possibilidade da nova relação turismo-natureza-comunidade local onde as atividades contemplativas (permeadas pela prática de lazer e turismo) e extrativistas, incentivam e orientam práticas responsáveis em áreas naturais protegidas. Deve-se, então, promover a participação dos interessados diretos na tomada de decisões relativas à gestão das Unidades de Conservação e consequentemente de seus usos.

Assim, esta pesquisa considera a importância destas duas categorias de manejo para a valorização e validação do TBC, pois estas garantem: a manutenção dos agentes locais no local herdado; a não possibilidade da privatização dos espaços e consequente chegada de agentes, grupos produtivos e econômicos externos; o uso racional dos recursos naturais renováveis. Ademais, garantem uma das principais premissas da perspectiva de TBC defendida nesse artigo: a concepção, o planejamento, a operações e gestão do turismo promovida pelos agentes locais.

\section{Referências bibliográficas}

BRASIL. Lei n. 9.985, de 18/07/2000. 4 Edição. Brasília: MMA/SBF, 2000.

BRASIL. Decreto n. 4.340, de 22/08/2002. 4ª Edição. Brasília: MMA/SBF, 2004.

BRITO, A.C.; FERREIRA, H.; MACHADO, M. Construção Coletiva da Gestão Participativa na Reserva Extrativista Prainha do Canto Verde - CE. Revista Práticas Inovadoras em Gestão de Unidades de Conservação. Brasília: ICMBio. Edição $\quad 01,2014 . \quad$ Disponível em $<$ http://www.icmbio.gov.br/praticasinovadoras/todas-as-praticas/215-pratica2014-48.html>. Acesso em 27/04/2015.

CORIOLANO, L.N.M.T. 2 ed. Do local ao Global: o turismo litorâneo cearense. Campinas: Papirus, 2001.

COSTA, G.V.L. A população do Aventureiro e a Reserva Biológica Estadual da Praia do Sul: conflitos e disputas sob tutela ambiental. Dissertação de 
mestrado: Rio de Janeiro: UFRRJ/Museu Nacional/Programa de Pósgraduação em Antropologia Social, 2004.

COSTA, G.V.L.; CATÃO, H.; PRADO, R.M. Praia do Aventureiro: um caso suis generis de gestão local do turismo. In: BARTHOLO, R.; SANSOLO, D.G.; BURSZTYN, I. (Org). Turismo de base comunitária: diversidade de olhares e experiências brasileiras. Rio de Janeiro: Letra e Imagem, 2009. p. 177-197.

FERREIRA, H.C.H. Redefinindo Territórios: preservação e transformação no Aventureiro - Ilha Grande (RJ). Dissertação de mestrado: Rio de Janeiro: UFRRJ/ICHS/CPDA, 2004.

MENDONÇA, T.C.M. Turismo e Participação comunitária: 'Prainha do Canto Verde a "Canoa" que não quebrou e a "Fonte" que não Secou?'. 2004. 192 f. Dissertação (Mestrado em Psicossociologia de Comunidades e Ecologia Social). UFRJ, Rio de Janeiro, 2004.

MENDONÇA, T.C.M.; FONTOURA, L.M. Reserva Biológica, Reserva de Desenvolvimento Sustentável ou Área de Proteção de Ambiental? Turismo, restrições e possibilidades na Vila do Aventureiro. Áreas Protegidas e Inclusão Social: Tendências e Perspectivas. Volume 1, Número 4, 2009, p. 235-237.

MENDONÇA, T.C.M. Que paraíso é esse? A turismização da llha Grande. Tese (Doutorado em Ciências Sociais) - Instituto de Filosofia e Ciências Humanas, UERJ, Rio de Janeiro, 2010.

MENDONÇA, T. C. de M.; BRANDÃO, L. O Povo do Aventureiro: turismo, recategorização e inclusão. In: XI Encontro Nacional de Turismo de Base Local - Turismo e transdisciplinaridade: novos desafios. Niterói, UFF, 2010, pp. 1140-1153.

MENDONÇA, T.C.M.; MORAES, E.A. (Orgs). O Povo do Aventureiro e o turismo de base comunitária: Experiências vivenciadas na Vila do Aventureiro - Ilha Grande, RJ. 1a edição. Rio de Janeiro: EDUR, UFRRJ, 2011.

MENDONÇA, T.C.M.; MORAES, E.A. de. Reflexões emergentes sobre turismo de base comunitária, à luz da experiência no "Paraíso Proibido": Vila do Aventureiro, Ilha Grande, Brasil. Journal of Tourism and Development, v.4, 2012, pp.1169-1183.

MENDONÇA, T.C.M.; MORAES, E.A.; COSTA, M.A.M. Turismo e pesca nas Reservas Extrativistas Marinhas de Arraial do Cabo (RJ) e da Prainha do Canto Verde (CE): possibilidades e limites de complementaridade. Caderno Virtual de Turismo. Rio de Janeiro, v. 13, n. 3, p.372-390, dez. 2013.

MORAES, E.A. et al. Unidades de Conservação de Uso Sustentável no Estado do Rio de Janeiro: Contexto e desafios na gestão. Anais do III Seminário Brasileiro de Áreas Protegidas e Inclusão Social. Teresópolis/RJ, 11 a 14 de novembro de 2007.

MORAES, E.A.; IRVING, M.A. Participação Social no Planejamento e Gestão do Ecoturismo em Reservas Extrativistas: Um Olhar de Base Comunitária. Anais do VII Congresso Nacional de Ecoturismo / III Encontro Interdisciplinar de Ecoturismo em Unidades de Conservação. Aracruz (ES): Instituto Capixaba de Ecoturismo, 17 a 22 de novembro de 2009. 
MORAES, E.A.; IRVING, M.A. Ecoturismo: encontros e desencontros na Reserva Extrativista do Cazumbá-Iracema (AC). Revista Brasileira de Ecoturismo, São Paulo, v.6, n.3, ago/out-2013, pp.738-757.

PRADO, R. As espécies exóticas somos nós: Reflexão a propósito do ecoturismo na llha Grande. Horizontes Antropológicos - Turismo, ํㅡㄹ 20, Ano 9, Porto Alegre: UFRGS, 2003a.

PRADO, R. A indigenização da Agenda 21: Reflexão a partir de um caso na Ilha Grande (Angra dos Reis, RJ). Anais do XXVII Encontro Anual da ANPOCS, Caxambu - MG, 2003b.

PRADO, R. De praias que viram morros e do valor da natureza. In: XIX Encontro Anual da ANPOCS. Caxambu-MG: 2005.

VILAÇA, A.; MAIA, A.A. O povo do Aventureiro. In: PRADO, R. (org.). Ilha Grande: do sambaqui ao turismo. Rio de Janeiro: Garamond/EDUERJ, 2006. p. 59-104.

WUNDER, S. Modelos de Turismo, florestas e rendas locais. In: PRADO, R. (org.). Illha Grande: do sambaqui ao turismo. Rio de Janeiro: Garamond/EDUERJ, 2006. p. 133-190.

\section{Nota:}

${ }^{1}$ A Área de Proteção Ambiental é uma área constituída por terras públicas ou privadas, com um certo grau de ocupação humana, dotada de atributos abióticos, bióticos, estéticos ou culturais especialmente importantes para a qualidade de vida e o bem-estar das populações humanas, e tem como objetivos básicos proteger a diversidade biológica, disciplinar o processo de ocupação e assegurar a sustentabilidade do uso dos recursos naturais (BRASIL, 2002).

Teresa Cristina de Miranda Mendonça: Universidade Federal Rural do Rio de Janeiro, Rio de Janeiro, RJ, Brasil.

E-mail: tecaturismo@yahoo.com.br

Link para o currículo Lattes: http://lattes.cnpq.br/4339255053628511

Edilaine Albertino de Moraes: Universidade Federal de Juiz de Fora, Juiz de Fora, MG, Brasil.

E-mail: edilainerumos@yahoo.com.br

Link para o currículo Lattes: http://lattes.cnpq.br/5450933897214464

Data de submissão: 28 de abril de 2015

Data de recebimento de correções: 17 de fevereiro de 2016

Data do aceite: 17 de fevereiro de 2016

Avaliado anonimamente 